\title{
A Web-based System to Enhance Lecture Interaction: Case Study at Sultan Qaboos University (SQU)
}

\author{
Ali Al Sulaimani \\ College of Computing and \\ Information Technology \\ Arab Academy for Science and \\ Technology
}

\author{
Essam Kosba \\ College of Computing and \\ Information Technology \\ Arab Academy for Science and \\ Technology
}

\author{
Yasser El-Sonbaty \\ College of Computing and \\ Information Technology \\ Arab Academy for Science and \\ Technology
}

\begin{abstract}
This study highlights the importance of using technology in increasing communication and interaction between students and teacher as a tool that helps access information through the fastest and latest technological methods. During this paper search a prototype has been developed named (InTeRaCt), and tested with random users, including students and teachers from SQU. The survey result which conducted from some users who tested the prototype was much stimulating, explaining how helpful such tool could support the interactivity between students and teachers, and affecting in positive way in student education process.
\end{abstract}

\section{Keywords}

Distance learning, E-learning, M-Learning, mobile apps.

\section{INTRODUCTION}

Contemporary societies are experiencing many challenges that imposes itself on the nature of life, the method of its work and its various organizations. Most prominent of these challenges that seen in those communities are the rapid development of information technology and modern communications, which contributed to the changing nature of life and form of institutions including educational institutions. From the past few years, the market for smart education has developed and has adopted the latest technology with the increasing demand from K-12 and higher education institutions [1].

Great advances in information and communication technology and the proliferation of electronic knowledge between school and university students resulted in the emergence of new forms of education systems. In the past decade, the tools of education and training emerged mainly from the computer and the methods of interaction with it by taking advantage of the CD- ROM and LAN. During the present century, the concept of Electronic Learning (e-learning) developed and its tools characterized using the Internet. Electronic Learning is a term that includes web-based instruction, online learning, and other technology-based training [2].

Tom defines mobile learning as a natural extension of elearning that has the potential to make learning even more widely available and accessible than what is used in existing eLearning environments [3]. Mobile learning allows the delivery of an educational method which, that could be more cost-effective than eLearning methods, not to mention that the ubiquity of mobile phones means that many people are already familiar with mobile phone applications [4]. Besides that, wireless and mobile technologies will help in distance learning for such as rural learners (who are without infrastructure for access) by making it easy to provide learning opportunities to them, and also to learners that continually on move (example business professionals).
Interaction and Communication play an important role in the learning process. They effectively enable m-learning by which it can contribute to the quality of education. Instead of remaining a passive recipient; Interactivity represents an opportunity for every learner to take hand in shaping the informational, communicational and learning process [5]. Thus, an active involvement of the learners has a great impact upon successful learning [6].

\subsection{Problem Statement}

The studies showed that in the traditional lecture setting there is a lack of interaction between a teacher and the students. This affects the learning motivation of the students. This lack of interaction is due to many reasons such as a. big classes with large number of students; which means that few students can only ask, b. Time Constraint; one or at most few students can interact with teacher at a certain time meaning that not all students can interact, and c. Psychological aspects; many students don't like to ask questions because they are too shy or because they think that their question is not good enough. Other reasons and issues regarding lack of lecture interaction are summarized later in this paper.

All these problems cause many students not to interact at all during the lecture. This motivates many research studies to solve the problem of poor interaction which at the end affects negatively the learning process and outcome. These studies presented some interactive systems such as a mobile device that could maintain a much higher level of student involvement.

As mentioned above, there are many mobile systems that have been developed for enhancing the lecture interaction but there are some limitations in these applications because some of them require specialized hardware, while some are applications for PDA's. They can't be used with a regular mobile phone. Moreover, there are few applications that concentrate on lecture interaction. In addition, some mobile learning systems such as Mobile Lecture Interaction, MLI [7] requires to be installed before using it. MLI has two user interfaces for students and teacher which needs more effort to install and configure and it works only during the lecture. Besides that, there are different mobile platforms such as Google Android, Apple iOS and Windows phone that need special requirements. Android itself has different versions and some applications work with specific version and doesn't work properly with another.

\subsection{Motivation}

As it was noticed before; that there are some difficulties in the interaction between students and teachers during the lectures. In addition to the problem of lack of interaction mentioned in the problem statement section, other difficulties could be due to the presence of male and female students in the same class. 
This makes both of them either shy or afraid to ask or interact especially with the first year students. Besides that, as a result to some traditional and social aspects in Oman, some female students are shy to ask male teachers while males don't interact freely with female teachers.

Although majority of students faces some difficulties with traditional face to face class interaction, they are fans of mobile devices especially smart phones. They spend a lot of time browsing and accessing applications. Accordingly, using mobile phones as a media of interaction would be a good solution to enhance learning process and outcome.

Lecture interaction plays a significant role in the learning process and outcome. Pedagogical studies proved that there is a lack of interaction between students and teacher which at the end affects the student's motivation to learn. This lack of interaction is due to many reasons which are summarized in the following points:

- In the traditional classrooms, the process of communication and interaction between teacher and students frequently unilateral from the teacher to the students. However, it is seldom bilateral when students answer the teacher's questions.

- In the famous learning pyramid lecture is shown to have the lowest retention rate $(5 \%)$ of different teaching methods, compared to for example demonstration (30\%) and practice by doing (70\%). At least to a certain extent the low retention rate is explained by the generally low interaction between the instructor and the students [8].

- The most common interaction form is asking questions during the lecture by raising the hand. However, this is at best difficult to do in such large lectures. The size of the audience effectively prevents the educator from answering the potentially large set of questions [9].

- In the large classrooms, one or at most few students can interact with teacher at a certain time. The majority of students will not profit from this form of interactivity.

- In lectures with large audience, not all students are able to ask questions because of time constraints.

- Finally, there is a fundamental problem in traditional lectures is the learner required to give continuous attention over 60 to 90 minutes. While usually, the attention span of a learner is only about 20 minutes. That period only can be afforded before the brain seeks other stimulation, either internal (e.g., daydreaming) or external ("Who is that walking down the hall?") [10].

\subsection{Objectives}

This study shares the latest developments regarding mobile learning projects in the western countries and propose a framework for the development and implementation of a Web-Based Lecture Interaction System $(\mathrm{InTeRaCt})$ for the students and teachers. It presents (InTeRaCt) for enhancing the lecture interaction between a teacher and the students. It supports the continuous interaction during and after the lecture with the help of most prevalent mobile devices.

The rest of paper consists, Section (2) reviews background and related work. Section (3) proposes the structure the proposed system (InTeRaCt). Section (4) introduces the System Prototype (InTeRaCt). Section (5) discuss the System Evaluation. Section (6) provides conclusions for this paper and discusses the future of work.

\section{LITERATURE REVIEW \\ 2.1 Background}

Education is a very important stage in the life of every human being and according to its importance, different educational methods appeared. Distance learning is one of these educational methods that meets the needs of people and their circumstances. It passed through many stages of development. This development is a continuous process and will never stop. Studies and researches elaborated on distance learning trying to find new ways to develop this type of education. Technology plays a significant role in the education system especially for those who are willing to learn at anytime and anywhere.

At the beginning of this century, electronic learning appeared given the humanity a great boon. It played a big role in spreading knowledge and facilitating the learning process. Assessing information from distributed database over network, constant updating of knowledge, and providing learning to learners with different age, sex, culture, education background, and personal interest are some advantages of electronic learning as compared to the traditional learning methods. Several e-Learning systems are available, for example, Moodle, eFront, Apex learning, and Blackboard learning system, etc... [11].

The rapid advances of wireless network and pervasive and ubiquitous computing has potential to enable anyone to learn anywhere at any time. Besides that, the spread of mobile devices especially among young people encourage to look for new method of learning called Mobile Learning or sometimes called M Learning [12]. A. Collins and Halverson, in (2009) suggested that: by understanding how new technologies can encourages children take responsibility for their own learning, society may help produce a generation of people who seek out ways to learn.

\subsection{Review of Related Studies}

In general, mobile phones play an important role to enhance the learning and teaching environment. If the teacher is not providing any innovation, the brain will go elsewhere [13]. Students enjoy using mobile devices and they seem to increase student's motivation.

The mobile devices such as Laptops, Cellular and Smart phones, and PDA, could be used in education for many purposes; as for communication with teachers and students [14], [15]. Taking the whole course as distance education [16], [17]. Accessing, and reading course materials [18], [19]. Taking exams or quizzes [20], [21]. Playing learning games [22]. In field studies [23]. Using other different activity programs during classes [24]. Tracking students' records, managing lessons, and online registration for courses.

Wadhvani and Roy mentioned in their recent study that [25]; One of the major constraints of mobile learning is the difficulty of developing learning environment for mobile users, since mobile devices can't be used in the same way as desktop computers. Because Mobile devices have distinct capabilities (limited computing powers and small size screens). In the other hand, each mobile devices differ from other devices by their hardware and software capabilities like 
computing power, screen resolution, operating system, web browser, etc.

There are many tools and applications that have been developed for enhancing lecture interaction. Some of these applications; 'Clickers' [26], which formally known as Personal Response Systems [27]. And ClassTalk [28], Discourse ClassInHands [29], ConcertStudeo [30], and Numina [31]. But there are many limitations in these applications since they could require specialized hardware, while some are applications for PDA's, and can't be used with a regular mobile phone.

During recent years, there were many mobile learning applications that were developed to enhance the learning process and outcome. Some of these systems require special hardware while some can be only used by some brands of mobile phones. Some of these systems are discussed in the following sections.

One of the applications in lecture interaction is "MLI" which stands for Mobile lecture Interaction [32]. MLI was presented to support all mobile phones. It allows the students to ask questions via their mobile phones. They can anonymously ask questions without mentioning their names. On the other hand, other students can vote for the listed questions and increase the number of votes per question. Then the teacher can give high priority of attention to the higher voted question and answer it in real time. Besides that, the system gives the teacher the ability to put the minimum number of votes per question so when this number is reached then a popup message will be shown to his/ her screen for more attention. MLI study proved that this system encouraged students to ask questions and increased the interaction during lecture especially for large audience classes. Moreover, it helped students to ask especially for those who think that their question is silly or not that good. However, there are many limitations of MLI as summarized below:

- First, this application considers only interaction during lectures and didn't consider other scenarios where students need assistance when they are at home, on move or without internet access.

- Second, it is unilateral (one way) from the students to the teacher and it doesn't allow the teacher to put comments or to answer students' questions by using the same application.

- Third, it doesn't allow students to interact and assist each other under the supervision of the teacher.

- Fourth, there is no evidence that MLI will work with any mobile device and platform.

- $\quad$ Fifth, MLI should be installed in each device before using it which means you have to install it manually for high number of students and teachers.

- Last but not least, since the students can ask questions anonymously, there is no record in the database about the students and their activities or whether they use the application or not.

After extensive piloting and experimentation in the area of mobile learning KU-SO Team has been developed KO-SU as an innovative mobile learning platform [33]. It is designed for everyone and anyone who wants to teach and learn via mobile devices. It should be installed as an app depending on the mobile platform such as Android and iOS. While KO-SU is wonderful mobile learning tool as an app, it is difficult to be used in mobile devices as a website. Also, teachers ask questions but students cannot.

Also Socrative Team help teachers in getting engage and assess with their students during the educational activities by developing Socrative tool which used by tablets, laptops and smartphones[34]. By using real time questioning, visualization, and instant result aggregation, teachers can measure the whole class' current level of understanding. Socrative saves teachers time so the class can further discuss, collaborate, extend and grow as a community of learners. In the other hand, Socrative only allows just teachers to ask questions and make quizzes while students only answer these questions. It doesn't allow student to put questions as the proposed system $(\mathrm{InTeRaCt})$

\section{THE PROPOSED SYSTEM (InTeRaCt)}

\subsection{System (InTeRaCt) Architecture}

In the development of the proposed prototype, different tools and resources have been used to get the best implementation for such system. The framework of the proposed system is shown figure 1.

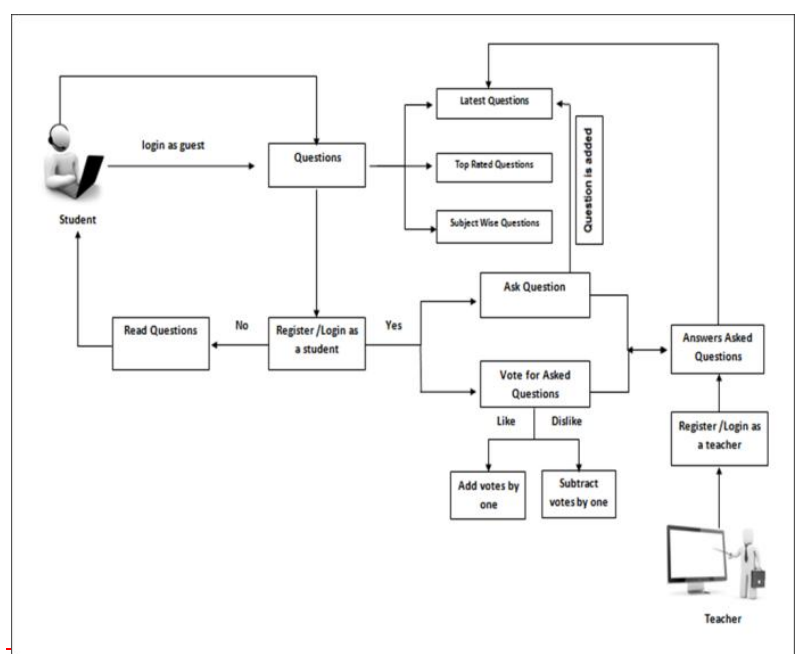

Figure 1: InTeRaCt General Framework

The overall structure of the prototype, can be easily understood with the help of this ER-Diagram.

This entire system has many tables but the major tables are explained in the above diagram. There are three users in the proposed prototype; super user who is the administrator of the system, faculty user who gives reply to the question asked by various students, and the student user who will ask questions to clarify their doubts.

Figure 2 shows the complete ERD for the proposed system providing graphical representation of database tables, and the sequence steps for user's actions. 


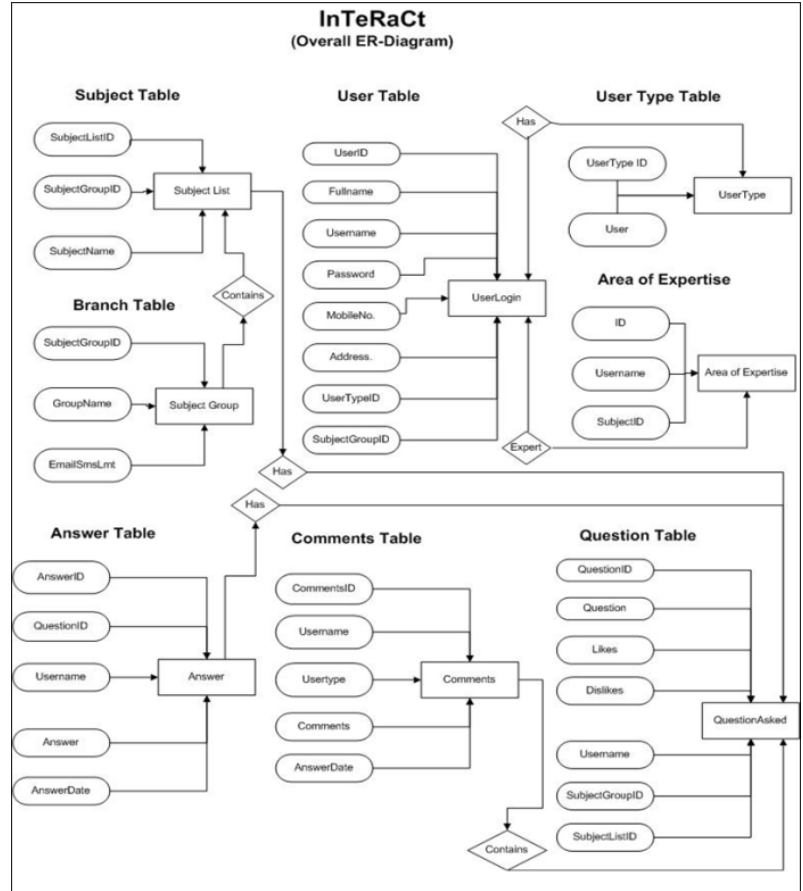

Figure 2: Proposed System ER Diagram

\subsection{How this prototype works?}

\subsubsection{From Student Prospective:}

Students have to fill the registration form and submit their details. Once they submit their details, two emails will be sent to their registered email address which they entered while filling the registration form. Those two emails are welcome and activation emails which contains their username and password. Users are supposed to check the activation email and click the activation link to activate their account.

After that, student can ask any question on any topic they have been registered in that topic class previously. Once a student asks a question, the faculties who belong to the same branch in that particular subject will get an email stating that a particular student has asked a question.

Other students can comment on that question and like and dislike that question. Like and dislike have impact on faculty reply. The more number of likes will force the faculty to give answer as SMS and email have been sent on each subject. Once the likes of a particular subject reach to a pre-set limit, the faculties will get an SMS and email on each like. When the faculty reply to the question, the students will get an email and SMS in their mobile.

\subsubsection{From Faculty Prospective:}

User Faculty is responsible for answering the questions asked by the students. Students ask questions by selecting the main group such as (Information Technology); then the subject such as (Visual Basics), and then they can ask their questions.

Also, faculty can change his subjects and add other subjects that belong to same group. Once a faculty registers in the website, the super user will activate his account. In the first time; the faculty will be asked to select the subjects he teach.

A Super user is the administrator in the proposed prototype. Super user can do the following things.

1. Add Group, and Subjects

2. Set Email Limit for each subject

\section{Suspend any user}

4. Resetting the user passwords and other credentials

\subsubsection{User Registration Module}

Only registered student/faculty can be able to ask questions, pass comments on any question and give like or dislike on any question or answer the question.

Figure 3, illustrates the registration form for students and teachers which they are the same. But students can activate their users by clicking on the activation link through the activation email while teachers are activated by the super user as mentioned before.

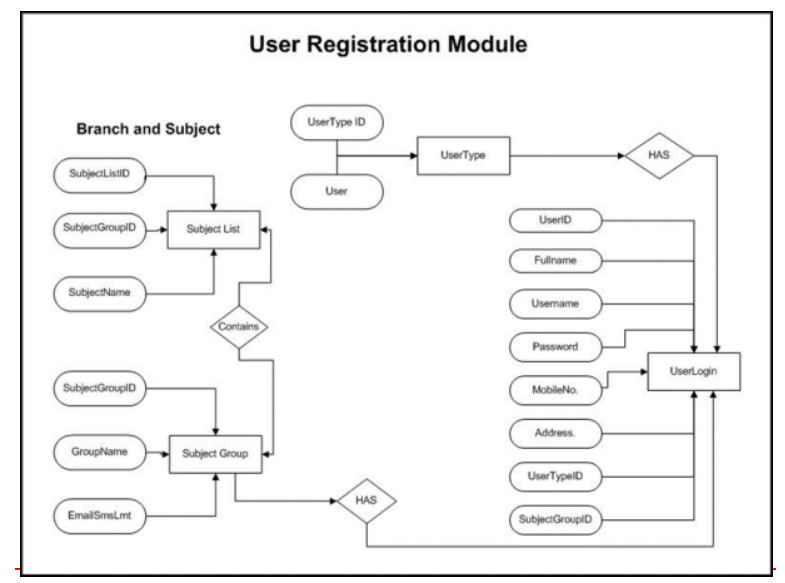

Figure 3: User Registration Module

\subsubsection{Question Module}

In question module, figure 4, shows how students can ask questions.

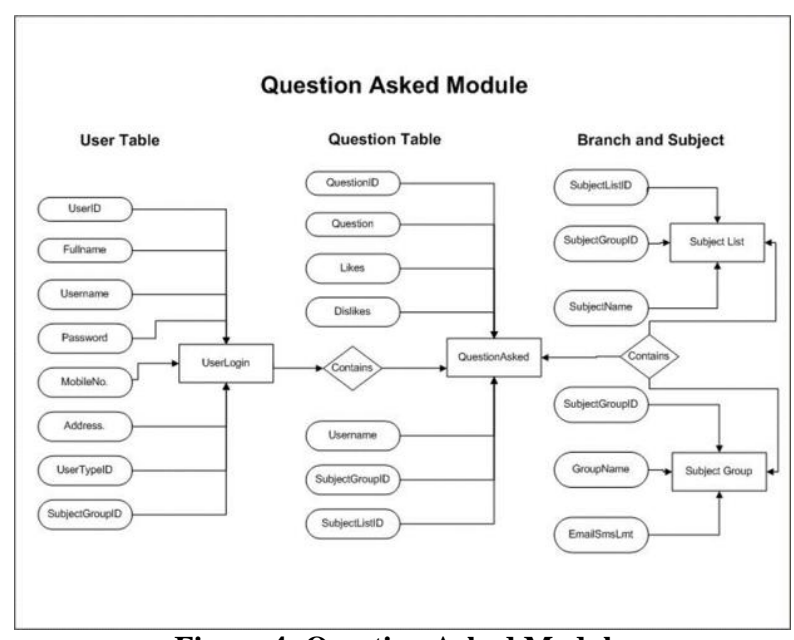

Figure 4: Question Asked Module

\subsubsection{Answer Module}

Figure 5, Demonstrates the answering module when the faculty user do answer the questions that where asked by student users. 


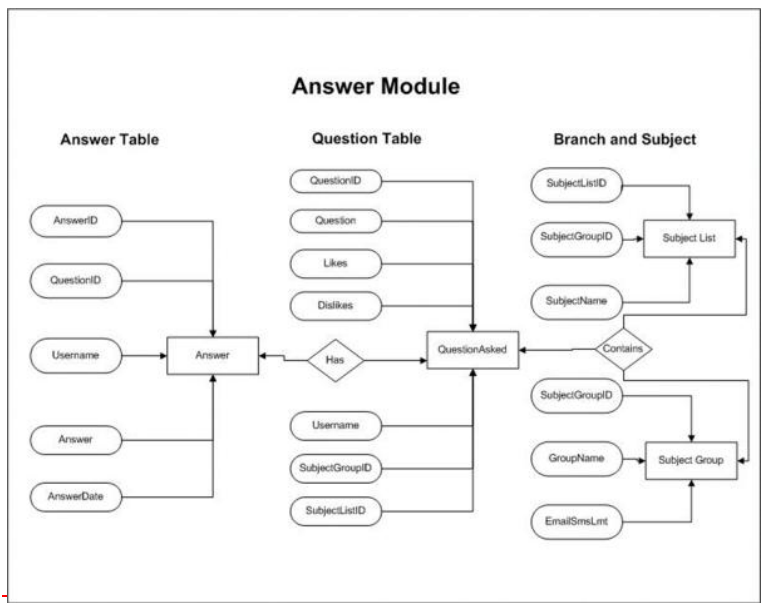

Figure 5: Answer Module

\subsubsection{Comments Module}

All registered users can comment on any questions. There is no limit for commenting on any question as shown in figure 6 .

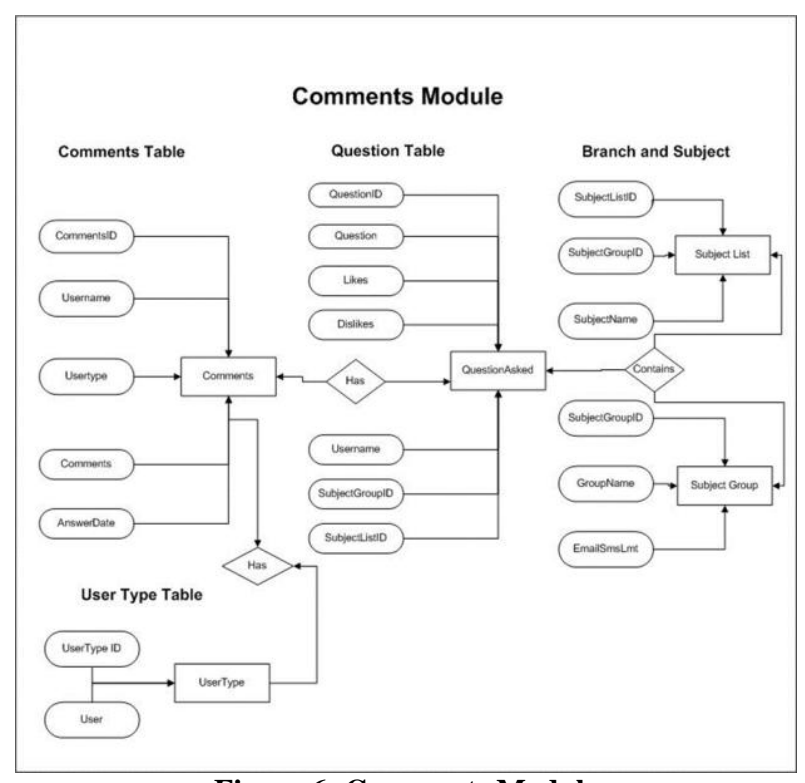

Figure 6: Comments Module

\subsubsection{Tools and Resources}

In the development process of InTeRaCt, the following tools and resources has been used. (Html 5, CSS 3, JQuery, Dreamweaver, PHP (Application Server), MYSQL (Database to save all the data), PHP MYADMI (Web Interface for MYSQL Database), CURL Script (For Sending SMSes))

\section{SYSTEM PROTOTYPE (INTERACT)}

In the proposed prototype, student will post or submit a question(s) to a particular group like commerce, computer science, Mathematics, Physics etc. In that group, different subjects are listed. For example a student wants to ask a question on C Programming, so he/she is supposed to select Computer Science and Engineering as group (Super User will take care of all these groups and subjects). The moment any student submits a question all the faculties of that particular group will get an email and SMS stating that a student have asked a question. Another things, will be activated when a question is posted, with that particular question: a- Likes and Dislikes, which is used as a measure for the importance of the asked question. For example; a student asked a question on $\mathrm{C}$ Programming and his question is liked by the other students.
So they press like button (only for registered user). The moment this particular question likes reach to a certain limit, the faculties of this group will get an SMS and email stating that more number of students like this question and please answer the question.

And b- Comments area, which is just for commenting on that particular question. Students and faculty can comment on that. Basically it's like a discussion forum.

The unregistered or guest can access the website just to see the topics and its answers given by the faculties. They can use the filters to sort topics and search the questions related to their subject in which they are interested. Home page is mentioned in figure 7 .

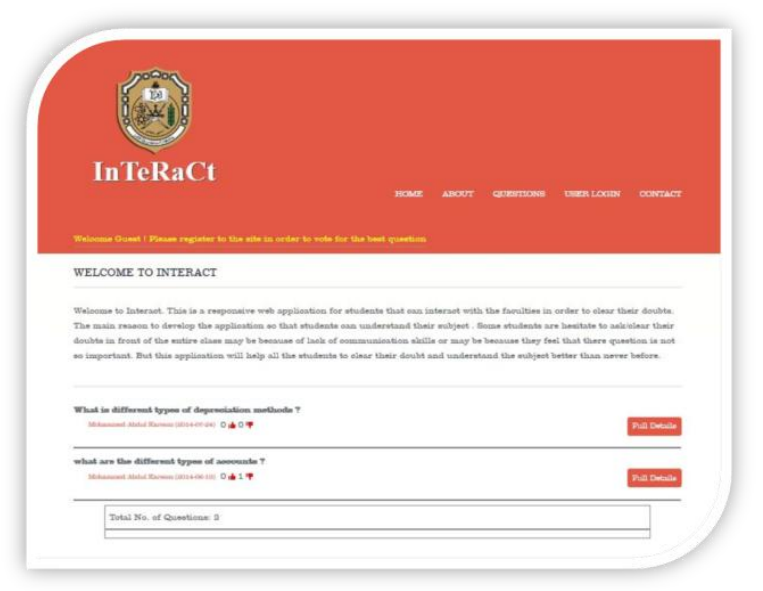

Figure 7: InTeRaCt Home Screen

There is a greeting line for the users. As figure 7 presents, greeting line for the guest is shown. And for registered user, the greeting line will show their name and user type (student, faculty). Home page also contains the latest questions, username who asks each question, date when the question was asked and the number of LIKES and DISLIKES to this question.

\subsection{Likes/Dislikes}

All the registered users can vote by clicking the likes/dislike on each question only once. This means that user can either like or dislike only once to each question. To do that, user has to login to his account and they have to go to the question and after that they have to click on $\mathrm{O}_{\mathrm{1}} 1 \mathrm{ip}$.

Once they click on any one of the thumb, it will change its color to RED. That means voting has been done. When the same student try to vote again, it will prompt that the vote is already casted.

\subsection{Comments}

All registered users can comment on any questions. There is no limit for commenting on any question. To see all answers given by the other users on this question, ANSWERS tab should be clicked.

\subsection{Users}

The proposed prototype has 4 types of users.

1. Super User (Prototype Administrator).

2. Faculties

3. Students.

4. Open Access (Guest) 
Whenever any user logged in to the website the main menu will add a new button based on their type like STUDENT, FACULTY or SUPER USER.

\section{SYSTEM EVALUATION}

This study depends on the analytical methodology by collecting data available in previous studies on "A Web-Based System to Enhance Lecture Interaction: Case Study at Sultan Qaboos University (SQU)". Texts and information are examined through commenting, organization, arrangement, listing and documentation according to their sources and references. This study belongs to case study researches, which aims to analyze and evaluate characteristics of a specific group. The purpose is to determine, classify, record and thoroughly analyze data and information collected to extract useful results, indications and conclusions as per known scientific steps.

The community of this case study is SQU students and their teachers during the academic year 2014-2015. The total number of respondents is (23), distributed as (10) boys, (9) girls, (1) teacher and (3) others.

Upon choosing the sample of the applied study, the current study has depended on the simple random method.

To conform to the study goals and question, data has been collected on the subject matter of the field study. The data is related to the answers of the sample individuals to the questionnaire on "A Web-Based System to Enhance Lecture Interaction: Case Study at Sultan Qaboos University (SQU)".

\subsection{Research Results}

Based on the survey analysis, the responses of the main question which is "Would you like to have a website / application that allows you to ask / answer questions about your courses?" there was statistical significance for the most frequent expression (Yes) in this question. As figure 8 showed that this sample of students and teachers realize the importance of using all types of technology in increasing communications and interaction among others.

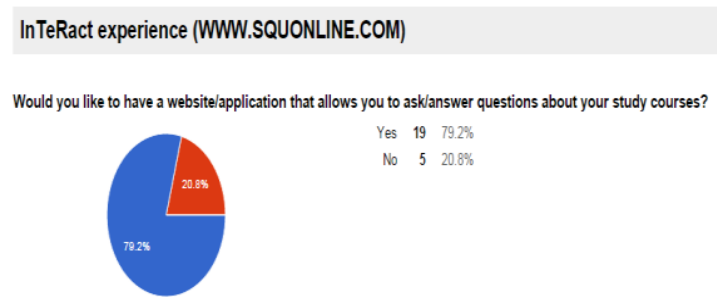

Figure 8: First Question Pie Chart Analysis

The importance of using technology to increase communication and interaction with others is evidenced by the use of cutting-edge technologies, which have become easily available in markets. This encourages using them in the educational process, particularly if there are learning software capable of transferring and simplifying information to the student as fast and precise as possible, driving the student to possess, continuously search for and actively communicate with such sophisticated and technologically centered learning software. By attracting students to such service, the community as a whole will avail.

Also regarding to another question: (Overall, I would like to use INTERACT for all of my courses. (For students only), which of the following objectives do you accomplish by using INTERACT?), the frequencies and percentage was calculated in the survey. There was statistical significance for the most frequent expression (Strongly agree) in this question as shown in figure 9.

\section{Overall, I would like to use InTeRaCt for all of my courses (For students only), Which of the following objectives do you accomplish by using InTeRaCt?}

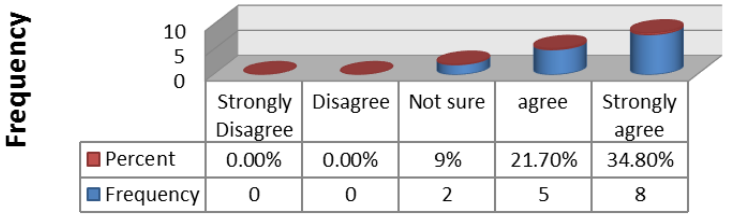

Figure 9: Student Opinions' About InTeRaCt Combo Chart Analysis

The final result collected from the survey is that: there is a real problem in the communication between students and their teachers, which many reasons could cause that as explained before, and using the technology to solve such problem is important in order to increase the interaction between them to enhance the learning process.

The proposed prototype InTeRaCt was accepted from the students and teachers and majority of the target group agreed to have this prototype in the learning methodology to break the ice between the teachers and students.

\section{CONCLUSION \& FUTURE WORK}

The motivation of this study was to shed light on one of the new educational formats that accompanied the tremendous progress in enormous development of communication, including wireless technology. It relies on the use of mobile technology and employment of electronic and mobile learning in the education.

In this paper, InTeRaCt was introduced to measure A WebBased System to Enhance Lecture Interaction: Case Study at Sultan Qaboos University (SQU)". 23 students and a teacher participated in the study during the academic year 2014-2015. Results showed that SQU students and teachers recognize the importance of using all types of technology to increase the interaction which lead to better educational environment and outcome.

InTeRaCt was developed as web based rather than a mobile app in order to work with all devices regardless of its hardware or software. Electronic and mobile learning works together as a technique to spread education process. Students can ask question or vote for any asked questions. They can login to the website as a guest or by registering. To have an option to ask or vote, they should register first. Guest user can see the latest asked questions, top rated, and subject wise questions. Students and teachers can use their desktops or mobile devices to access InTeRaCt. A customized mobile version of InTeRaCt was also developed to suit with multiple mobile devices. Users of InTeRaCt are notified with Short Messaging System (SMS) and email for any events such as new question, reply to a question and answer from the teacher to any question.

The major contributions of this thesis can be summarized below:-

1. Introduction of an easy-to-use website (InTeRaCt) to solve the problem of lack interaction between students and their teachers.

2. The website works with all devices regardless of its software and hardware. 
3. The proposed website helps students to ask questions at any time at any place.

4. The proposed website helps teachers to know the student's difficulties and try to solve them

As a complement to the requirements of this research, the researcher suggest the following research and scientific studies:

1. Applying the current study to the largest sample to cover all higher education institutions, including universities, colleges and institutes.

2. Applying the current study to demographic variables (such as gender, length of service, number of courses, etc.).

3. Applying the current study to schoolchildren and staff in the ministries in the Sultanate of Oman.

4. Carrying out a study in all the state's institutions, taking into account recent developments in the use of modern technology to communicate and interact with others.

5. Conducting a study to identify the obstacles faced by workers in government ministries regarding the use of technology.

6. Conducting a scientific study to identify the relationship between the use of technology and other variables (such as total quality management, decision making, leadership, professional pressures, administrative creativity ... etc.).

\section{REFERENCES}

[1] Normans Media Ltd, (2014). Smart Education \&Learning Market by Hardware: IWB \&SBL, Software: LMS/LCMS, Open Source \&Mobile Education Apps, Educational Content: Digital Content, Test And Assessment \&Digital Text Book - Global Advancements, Market Forecast and Analysis (2014 - 2019)

[2] Wadhvani and Roy, 2012. Developing Agent Oriented Mobile Learning System. (IJCSIS) International Journal of Computer Science and Information Security, Vol. 10, No. 4, April 2012.

[3] Tom H Brown, 2005, towards a model for m-learning in Africa, Title of article submitted to the South African Journal for Higher Education, South Africa, 2005.

[4] Mobile learning in developing nations. International Review of Research in Open and Distance Learning, 9(2). Retrieved from http://www.irrodl.org/index.php/irrodl/article/view/564/1 071

[5] Cruz, Ojala, and Korhonen, 2008. MOBILE LECTURE INTERACTION: MAKING TECHNOLOGY AND LEARNING CLICK, IADIS International Conference Mobile Learning 2008, 2008, Finland

[6] Krause, F. and Effelsberg, W., 2003. The Interactive Lecture: A new Teaching Paradigm based on Pervasive Computing. Proc. International Conference on Computer Support for Collaborative Learning 2003 - Community Events, Bergen, Norway, 135-137.

[7] Cruz, Ojala, and Korhonen, 2008. MOBILE LECTURE INTERACTION: MAKING TECHNOLOGY AND
LEARNING CLICK, IADIS International Conference Mobile Learning 2008, 2008, Finland

[8] Cruz, Ojala, and Korhonen, 2008. MOBILE LECTURE INTERACTION: MAKING TECHNOLOGY AND LEARNING CLICK, IADIS International Conference Mobile Learning 2008, 2008, Finland

[9] Henning Bär, Erik Tews, Guido Rößling, 2005. IMPROVING FEEDBACK AND CLASSROOM INTERACTION USING MOBILE PHONES, IADIS International Conference Mobile Learning 2005, 2005 , Germany

[10] Cruz, Ojala, and Korhonen, 2008. MOBILE LECTURE INTERACTION: MAKING TECHNOLOGY AND LEARNING CLICK, IADIS International Conference Mobile Learning 2008, 2008, Finland

[11] Wadhvani and Roy, 2012. Developing Agent Oriented Mobile Learning System. (IJCSIS) International Journal of Computer Science and Information Security, Vol. 10, No. 4, April 2012.

[12] Kathryn 2012: A. Collins and Halverson 2009. THE PERCEPTION OF TEACHERS TOWARD THE USE OF MOBILE TECHNOLOGY AS A TOOL TO ENGAGE STUDENTS IN LEARNING, A Dissertation Presented to The College of Graduate and Professional Studies Department of Educational Leadership Indiana State University Terre Haute, Indiana, May 2012.

[13] Perry, D., 2000. How The Brain Learns Best, Instructor Magazine, Nov/Dec 2000, 34-37.

[14] Lim, C.P. and Lee, C.B., 2002. Exploring WAP Technologies: Mediating E-Discussions in Learning Communities, Journal of Instructional Science and Technology, and 5(1).

[15] Seppala, P. and Alamaki, H., 2003. Mobile learning in teacher training. Journal of Computer Assisted Learning, 19(3), 330-335.

[16] Giunta, G., 2002. Student Use of Mobile Learning in Italy. Technical report, Department of Education Science, University of Rome, Italy http://learning.ericsson.net/mlearning2/project_one/stude nt_use_year_2_roma_tre.doc.

[17] Roberts, J., 2003. Harvesting fragments of time. Mobile learning pilot project. Technical report, McGraw-Hill. http://www.mcgrawhill.ca/college/mlearning/mlearn_rep ort.pdf.

[18] Waycott, J., 2002. An Evaluation of the Use of PDAs for Reading Course Materials. Proc. IEEE International Workshop on Wireless and Mobile Technologies in Education, Växjö, Sweden.

[19] Meisenberger M., Nischelwitzer A., 2004. The Mobile Learning Engine (MLE) - a mobile computer-aided, multimediabased learning application. Proc. Multimedia Applications in Education Conference, Graz, Austria.

[20] Homan, S. and Wood, K., 2003. Taming the MegaLecture: Wireless Quizzing. Syllabus Magazine, October 2003.

[21] Whattananarong, K., 2004. An Experiment in the Use of Mobile Phones for Testing at King Mongkut's Institute of Technology North Bangkok, Thailand. Proc. International Conference on Making Education Reform 
Happen: Learning from the Asian Experience \& Comparative Perspectives, Bangkok, Thailand.

[22] Ketamo, H., 2002. mLearning for Kindergarten's Mathematics Teaching. Proc. IEEE International Workshop on Wireless and Mobile Technologies in Education, Växjö, Sweden.

[23] Rieger R. and Gay, G., 1997. Using Mobile Computing to Enhance Field Study. Proc. Computer Support for Collaborative Learning '97, Toronto, Canada, 215-223.

[24] Tatar, D. et al., 2003. Handhelds Go to School: Lessons Learned. IEEE Computer, September 2003, 30-37.

[25] Wadhvani and Roy, 2012. Developing Agent Oriented Mobile Learning System. (IJCSIS) International Journal of Computer Science and Information Security, Vol. 10, No. 4, April 2012.

[26] H-ITT, 2007. Classroom Response System. http://www.h-itt.com/

[27] Duncan, D., 2005. Clickers in the Classroom: How to Enhance Science Teaching Using Classroom Response Systems. Addison-Wesley.

[28] ClassInHands, 2007. Wake Forest University, USA. http://classinhand.wfu.edu/. ClassTalk, 2007. The
Classroom Communication System. http://www.bedu.com/classtalk.html.

[29] Dawabi, P. et al., 2003, ConcertStudeo: Using PDAs to support face-to-face learning. Proc. International

[30] ClassInHands, 2007. Wake Forest University, USA. http://classinhand.wfu.edu/. ClassTalk, 2007. The Classroom Communication System. http://www.bedu.com/classtalk.html.

[31] Heath B., 2005. Project Numina: Enhancing Student Learning with Handheld Computers. IEEE Computer, June 2005.

[32] Cruz, Ojala, and Korhonen, 2008. MOBILE LECTURE INTERACTION: MAKING TECHNOLOGY AND LEARNING CLICK, IADIS International Conference Mobile Learning 2008, 2008, Finland

[33] KU-SO Team, 2015. Retrieved from https://kosu.com/faq.php on 9/9/2014, KU-SO FAQ: Tell me more about KO-SO.

[34] Socrative Team, 2015. . Retrieved from http://www.socrative.com/index.php on 9/9/2014, Socrative Homepage: About Socrative. 